\title{
Prevalence of diarrhea and associated factors among under-five children in Bahir Dar city, Northwest Ethiopia, 2016: a cross-sectional study
}

Amare Belachew Dagnew* ${ }^{*}$, Tilahun Tewabe, Yihun Miskir, Tariku Eshetu, Wosin Kefelegn, Kidanu Zerihun, Mekonnen Urgessa and Tiruha Teka

\begin{abstract}
Background: In Ethiopia, morbidity and mortality due to diarrhea is significantly high. Most importantly, burden of diarrhea is disproportionately high among under-five children. Therefore, the objective of this study was to assess the prevalence and factors associated with diarrhea among children younger than 5 years old in Bahir Dar city, Northwest, Ethiopia, 2016.

Methods: This community-based cross-sectional study was conducted among under-five years-old children from March 24 to April 12, 2016. Systematic sampling technique was used to select 498 households. Data were collected by using an interviewer administered questionnaire. Both bivariate and multivariate logistic regression analyses were employed to identify predictor variables. Factors with a $p$-value of $<0.05$ were considered as independently associated with diarrhea.

Results: The 2 weeks prevalence of diarrhea among under five children was 14.5\%. Lack of hand washing facilities in the household $(A O R=3.910(1.770,8.634))$, lack of separate feeding materials ( $A O R=5.769(1.591,9.220))$, poor hand washing practice $(A O R=6.104(2.100,17.738))$ and not breastfeeding $(A O R=2.3(1.023,5.46))$ were predictors of the concurrence of diarrhea.
\end{abstract}

Conclusions: The prevalence of diarrhea in the study area was slightly higher than the 2016, Ethiopian Demography and Health Survey finding which was 12\%. Thus, improving handwashing facilities and practices, serving the food to the child with a separate materials and encourage optimal breastfeeding were recommended.

Keywords: Diarrhea, Under -five children, Bahir Dar, Ethiopia

\section{Background}

Diarrhea is thepassage of three or more watery or loose stools per day, and when the mother considered as increased stool frequency or liquidity [1]. The acute diarrhea causes high loss of water and salts from a body which results in either severe dehydration and death within a short period of time or predisposes children to malnutrition and makes them more susceptible to other infections [2].

\footnotetext{
* Correspondence: dagnewamare@gmail.com; amaredeje2010@gmail.com Bahir Dar University, College of Medicine and Health Sciences, Bahir Dar, Ethiopia
}

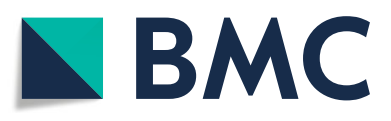

( ) The Author(s). 2019 Open Access This article is distributed under the terms of the Creative Commons Attribution 4.0 International License (http://creativecommons.org/licenses/by/4.0/), which permits unrestricted use, distribution, and reproduction in any medium, provided you give appropriate credit to the original author(s) and the source, provide a link to the Creative Commons license, and indicate if changes were made. The Creative Commons Public Domain Dedication waiver (http://creativecommons.org/publicdomain/zero/1.0/) applies to the data made available in this article, unless otherwise stated.
Globally, around 1.3 million people were died due to diarrhea and of the total deaths about 0.54 million were children's of under-five years of age. Majority of the mortality were occurred in developing countries [3]. Diarrhea is the second most cause of mortality and morbidity of under-five childhood illnesses in sub-Saharans Africa countries. In these countries, only $40 \%$ of people living in urban setting were accessing improved sanitations [3] and $72 \%$ of the people in Ethiopia were living without improved sanitation facilities [4].

Diarrhea is a highly prevalent disease in Ethiopia. In fact, it is the second leading cause of deaths $[2,3]$. A 
previous 2 week survey showed that prevalence of diarrhea among children under 5 years old was 13\% [3].

Different studies in Ethiopia showed that, socioeconomic status, monthly income, number of under-five children, methods of complementary feeding, types of water storage equipment, mother's poor hand washing practices, lack of hand washing facilities, duration of breastfeeding and improper waste disposal practices were significant factors for diarrhea occurrences [5-9].

Identifying the contributing factors of diarrhea is very important for the effective implementation of child health programs and prioritizations. There is a considerable variation in prevalence and determinant factors for diarrhea occurrence in Ethiopia. Despite the interventions and innovations undertaken regarding childhood diarrhea, the burden of the disease is high in the current study area. Therefore, this study was conducted to assess the magnitude and associated factors of diarrhea among under 5 years old children in Bahir Dar city, North West, Ethiopia.

\section{Methods}

\section{Study participants and period}

A community based cross sectional study was conducted among under five children from 24 March to 12 April, 2016, in Bahir Dar city, Amhara Regional State, Ethiopia. Bahir Dar city has nine sub cities and 18 kebeles. The current population size of the city is 318,429 . There are two public hospitals, two private hospitals and 9 health centers in the city.

\section{Sample size determination and sampling techniques}

The sample size was calculated using a single population proportion formula with consideration of the following assumptions: Prevalence $(\mathrm{P})=18 \%$ which is the prevalence of diarrhea in Mecha district, North West Ethiopia [10], confidence level (CL) 95\%, margin of error (d) $=5 \%$, design effect $=$ two (Bahir Dar city- sub city -kebeleshouseholds) and 10\% non- response rate. Thus, the final calculated sample size was 499. Household numbers having under-five children were taken from health extension workers registration books. The sampled households were proportionally allotted to each selected kebeles. Systematic sampling technique was used to select households from each kebele. The first household was selected using the lottery method among fife households, while the rest households, were selected every fifth interval.. The youngest child was selected for a household having two or more under 5 years of children.

\section{Data collection tools and procedures}

Data were collected from mothers/primary care takers using an interviewer-administered questionnaire and observation checklists. The questionnaire was adapted from previous research done on a similar topic $[5,6,10]$ and customized accordingly. A two-week recall method was used to assess the prevalence of diarrhea. Data collectors and supervisors were recruited for data collection. The supervisors and data collectors were trained about interview methods, consent and ethical aspects during data collection.

\section{Statistical analysis}

The questionnaire was checked visually for completeness and coding was given. The data was entered into Epi-info version 3.5.4 and exported to SPSS version 21.0 software for analysis. Frequency tables were used to summarize the socio-demographic characteristics' of the study participants and magnitude of diarrhea. Then, bivariate logistic regression was performed for each independent variable with the outcome variable and those variables with a $p$-value of $<0.05$ were adjusted into the final model (multivariate analysis). Finally, those variables having a $P$ value less than 0.05 were declared as statistical significant.

\section{Operational definition}

Diarrhea: The occurrence of loose or watery diarrhea at least three times per day in the previous 2 weeks, as reported by the mother/caretaker of the child [5].

Mixed feeding: An infant who took both breast milk and other food or liguid before his/her six months of age.

\section{Results}

\section{Socio-demographic-characteristics}

Of 499 households, 498 were included in this study with a response rate of $99.8 \%$. More than half of mothers' age $(54.8 \%)$ was between in the age group of 25 and 34 years with the mean age of 28.94 years ( $\pm 7.61 \mathrm{SD})$. Two hundred five (41.2\%) mothers attended primary level of education and $55.2 \%$ were housewives by ocuupations. The mean family size of the households was $4.43( \pm 1.37 \mathrm{SD})$ persons, meanwhile most $(86.3 \%)$ of the house-hold had only one under-five children in the family [Table 1].

\section{Environmental characteristics of the households}

Two hundred eighty-six (57.4\%) and 477 (95.8\%) of the households had the dwelling with the mud floor and corrugated iron roof, respectively. A majority of the households had a latrine and hand washing facility which accounts 96.4 and $60.2 \%$, respectively. About $64.2 \%$ of households had private latrine and from them $30.6 \%$ were not improved in type. Most households (95.6\%) disposed their waste materials properly. All households were pipe water users and most $(78.3 \%)$ of the households consumed more than 201 water per day [Table 2]. 
Table 1 Socio-demographic characteristics of households in BahirDar City, Amhara region, Ethiopia, 2016

\begin{tabular}{|c|c|c|c|}
\hline Variables Name & Category & Frequency $(n=498)$ & Percent \\
\hline \multirow[t]{2}{*}{ Household family size } & Four and less & 304 & 61.0 \\
\hline & More than four & 194 & 39.0 \\
\hline \multirow[t]{2}{*}{ Number of under five children in the house } & One child & 430 & 86.3 \\
\hline & Two and above & 68 & 13.7 \\
\hline \multirow[t]{2}{*}{ Relation of respondents to the child } & Mother & 385 & 77.3 \\
\hline & Caretaker & 113 & 22.7 \\
\hline \multirow[t]{3}{*}{ Age of mothers } & $18-24$ & 130 & 26.1 \\
\hline & $25-34$ & 273 & 54.8 \\
\hline & 35 and above & 95 & 19.1 \\
\hline \multirow[t]{2}{*}{ Marital status of mothers } & Married & 386 & 77.5 \\
\hline & Others & 112 & 22.5 \\
\hline \multirow[t]{2}{*}{ Religion } & Orthodox & 415 & 83.3 \\
\hline & Others & 83 & 16.7 \\
\hline \multirow[t]{3}{*}{ Occupation of mothers } & Employed & 73 & 14.7 \\
\hline & Housewives & 275 & 55.2 \\
\hline & Others & 150 & 30.1 \\
\hline \multirow[t]{3}{*}{ Education status of mothers } & No formal education & 110 & 22.1 \\
\hline & Primary & 205 & 41.2 \\
\hline & Secondary and above & 183 & 36.7 \\
\hline \multirow[t]{3}{*}{ Education of fathers } & No formal education & 41 & 8.2 \\
\hline & Primary & 95 & 19.1 \\
\hline & Secondary and above & 362 & 72.7 \\
\hline \multirow[t]{3}{*}{ Occupation of fathers } & Government employee & 192 & 38.6 \\
\hline & Merchant & 227 & 45.6 \\
\hline & Others & 79 & 15.9 \\
\hline
\end{tabular}

\section{Behavioral characteristics of the respondent}

Most (81.1\%) of the respondents practiced mixed feeding. More than one-third (37.6\%) of respondents had fed cow's milk to their children. About $88.6 \%$ of caregivers reported that they wash their hand using soap with water. However, one-fourth of caregivers didn't wash their hands after cleaning the child.On the other hand more than three fourth $(74.8 \%)$ of respondents used a cup and spoon to feed their children [Table 3].

\section{Demographic and health characteristics of the indexed children}

More than half (53.8\%) of the children were males and the mean age of the children was $21.07( \pm 14.4$ SD) months. Almost all of the children received measles and Rotavirus vaccine which is (97.9\%) and (97.1\%), respectively. Seventy two (14.5\%) children had diarrhea during the 2 weeks at the time of data collection [Table 4].

\section{Factors associated with childhood diarrhea}

Bivariate analysis was done and variables having a $(P$ value of leass than $<0.05$ ) were enrolled to the multivariable analysis for association testing. Those variables having a $p$ value of less than 0.05 were declared as significantly associated with diarrhea.

Children living in households with no hand washing facilities were around four times more likely to develop diarrhea than their counterparts $([\mathrm{AOR}=3.91(1.770,8.634)]$. Additionally, Children whose mother used only water to wash their hand were six times more likely to develop diarrhea than children whose mother used water with soap to wash their hands [AOR: 6.104 (2.100, 17.738)].

Regarding feeding practices of the child, non exclusive breastfed children were 2.3 times more likely to develop diarrhea than children who fed breast milk only during the first 6 months of life [AOR: 2.3 (1.023, 5.46) [Table 5]. Again, children who did not use separate feeding materials were six times at high risk to develop diarrhea than children who used their own material for feeding [AOR = $5.769(1.591,9.220)]$ [Table 5]. 
Table 2 Environmental characteristics of the households in Bahir Dar city, Amhara region, Ethiopia, 2016

\begin{tabular}{|c|c|c|c|}
\hline Name of variables & Category & Frequency $(n=498)$ & Percentage \\
\hline \multirow[t]{2}{*}{ Household floor type } & Mud & 286 & 57.4 \\
\hline & Cement & 212 & 42.6 \\
\hline \multirow[t]{2}{*}{ Household roof type } & Corrugated iron & 477 & 95.8 \\
\hline & Others & 21 & 4.2 \\
\hline \multirow[t]{2}{*}{ Hand wash facilities } & Yes & 300 & 60.2 \\
\hline & No & 198 & 39.8 \\
\hline \multirow[t]{2}{*}{ Latrine availability } & Yes & 480 & 96.4 \\
\hline & No & 18 & 3.6 \\
\hline \multirow[t]{2}{*}{ Type of latrine $(n=480)$} & Improved & 333 & 69.4 \\
\hline & Not improved & 147 & 30.6 \\
\hline \multirow[t]{2}{*}{ Owner ship of latrine $(n=480)$} & Private & 308 & 64.2 \\
\hline & Shared & 172 & 35.8 \\
\hline \multirow[t]{2}{*}{ Faces seen in the pit hole $(n=480)$} & Yes & 52 & 10.8 \\
\hline & No & 428 & 85.9 \\
\hline \multirow[t]{2}{*}{ Faces seen around the compound $(n=498)$} & Yes & 34 & 6.8 \\
\hline & No & 464 & 93.2 \\
\hline \multirow[t]{2}{*}{ If no latrine where they use $(n=18)$} & Open field & 16 & 88.9 \\
\hline & Others & 2 & 11.1 \\
\hline \multirow[t]{2}{*}{ Refuse disposal method $(n=498)$} & Proper & 476 & 95.6 \\
\hline & Improper & 22 & 4.4 \\
\hline \multirow[t]{2}{*}{ Water storage container } & Jerry can & 360 & 72.3 \\
\hline & Others & 138 & 27.7 \\
\hline
\end{tabular}

Table 3 Behavioral characteristics of the respondents in Bahir Dar city, Amhara Region, Ethiopia, 2016

\begin{tabular}{|c|c|c|c|c|}
\hline \multicolumn{2}{|l|}{ Variable type } & Category & Frequency $(n=498$ & Percentage \\
\hline \multirow{2}{*}{\multicolumn{2}{|c|}{ The child take other food than breast feed }} & Yes & 404 & 81.1 \\
\hline & & No & 94 & 18.9 \\
\hline \multirow{4}{*}{\multicolumn{2}{|c|}{ Type of food the child take mostly $(n=404)$}} & Cow's milk & 152 & 37.6 \\
\hline & & Gruel & 118 & 29.2 \\
\hline & & Adult food & 44 & 10.9 \\
\hline & & Others & 90 & 22.3 \\
\hline \multirow{3}{*}{\multicolumn{2}{|c|}{ Child feed method $(n=404)$}} & Hand & 53 & 13.1 \\
\hline & & Cup \&spoon & 302 & 74.8 \\
\hline & & Bottle & 49 & 12.1 \\
\hline \multirow[t]{8}{*}{ Hand washing } & Before food preparation & Yes & 377 & 75.7 \\
\hline & & No & 121 & 24.3 \\
\hline & Before eating & Yes & 483 & 97 \\
\hline & & No & 15 & 3 \\
\hline & After visiting latrine & Yes & 447 & 89.8 \\
\hline & & No & 51 & 10.2 \\
\hline & After cleaning child's bottom & Yes & 377 & 75.7 \\
\hline & & No & 121 & 24.3 \\
\hline \multirow{2}{*}{\multicolumn{2}{|c|}{ Hand washing method }} & Water \& soap & 441 & 88.6 \\
\hline & & Water only & 57 & 11.4 \\
\hline
\end{tabular}


Table 4 Demographic and health characteristics of the indexed children in Bahir Dar City, Amara region, Ethiopia, 2016

\begin{tabular}{|c|c|c|c|}
\hline Name of variables & Category & Frequency $(n=498)$ & Percent \\
\hline \multirow[t]{4}{*}{ Age of Child (in month) } & Eleven month and less & 145 & 29.1 \\
\hline & $12-23$ & 152 & 30.5 \\
\hline & $23-34$ & 98 & 19.7 \\
\hline & Greater than 35 & 103 & 20.7 \\
\hline \multirow[t]{2}{*}{ Sex of Child } & Male & 268 & 53.8 \\
\hline & Female & 230 & 46.2 \\
\hline \multirow[t]{2}{*}{ Duration of Breast Feeding } & Less than 24 months & 403 & 76.5 \\
\hline & Greater than or equal to24 months & 95 & 23.5 \\
\hline \multirow[t]{3}{*}{ Current Breast Feeding Status } & Exclusive Breast Feeding & 83 & 16.7 \\
\hline & Partial Breast Feeding & 289 & 58.0 \\
\hline & No Breast Feeding & 126 & 25.3 \\
\hline \multirow[t]{3}{*}{ Age at complementary Feeding } & Less than Six Month & 94 & 18.8 \\
\hline & At Six Month & 355 & 71.2 \\
\hline & Greater than Six month & 49 & 10 \\
\hline \multirow[t]{2}{*}{ Measles Vaccine(n498) } & Yes & 484 & 97.1 \\
\hline & No & 14 & 2.9 \\
\hline \multirow[t]{2}{*}{ Rota Virus Vaccine $(n=498)$} & Yes & 484 & 97.1 \\
\hline & No & 14 & 2.9 \\
\hline \multirow[t]{2}{*}{ Prevalence of Diarrhea } & Yes & 72 & 14.5 \\
\hline & No & 426 & 85.5 \\
\hline
\end{tabular}

\section{Discussion}

The two weeks prevalence of childhood diarrhea among under-five years-old in this study was $14.5 \%$. This finding is higher than studies done in East Gojjam zone, 6.5\% [11] and EDHS 2016 report, 12\% [12]. However, the current result is lower than west Gojjam zone, $18 \%$ [10], Egypt, 19.5\% [13], Ghana, 19.2\% [14], Eastern Ethiopia, 22.5\% [8], Iraq, 21.3\% [15], India 25.2\% [16] Burundi, 32.6\% [17], Arba-Minch rural community, 31\% [18], and Benshangul gumz, 22.1\% [19]. This may be due

Table 5 Multivariate analysis on determinants of under-five diarrhea in Bahir Dar City, Amhara region, Ethiopia, 2016

\begin{tabular}{llllll}
\hline Name of Variables & Category & Yes & No & COR $(95 \%$ C.I) & AOR (95\% C.I) \\
\hline Hand wash facilities & No & $46(23.2)$ & $152(76.8)$ & $3.189(1.896,5.365)$ & $3.910(1.770,8.634)$ \\
& Yes & $26(8.7)$ & $274(91.3)$ & 1 & \\
Separate material for the child feeding & No & $20(45.5)$ & $24(54.5)$ & $4.936(2.546,9.571)$ & $5.769(1.591,20.920)$ \\
& Yes & $52(14.4)$ & $308(85.6)$ & 1 & \\
Ownership of Latrine & Shared & $32(18.6)$ & $140(81.4)$ & $2.28(1.324,3.947)$ \\
& Private & $28(9.1)$ & $280(90.9)$ & 1 & \\
Type of Latrine & Not improved & $35(23.8)$ & $112(76.2)$ & $3.850(1.206,6.720)$ \\
& Improved & $25(7.5)$ & $308(92.5)$ & 1 & \\
Hand washing practice & Water Only & $21(36.8)$ & $36(63.2)$ & $4.461(2.418,8.228)$ \\
& Water and soap & $51(11.6)$ & $390(88.4)$ & 1 & $6.104(2.100,17.738)$ \\
Breastfeeding & No BF & $23(18.3)$ & $103(81.7)$ & $5.955(1.727,20.537)$ \\
& Partially BF & $46(15.9)$ & $243(84.1)$ & $5.048(1.528,16.675)$ \\
Faces around the compound & EBF & $3(3.6)$ & $80(96.4)$ & 1 \\
& No & $59(12.7)$ & $405(87.3)$ & $4.249(2.020,8.939)$ \\
\hline
\end{tabular}


to; the current study setting consider only urban dwellers; differences in socio-demographic characteristics, environmental factors (climate and geographical differences) and behavioral factors (availability of water, presence and usage of latrine, availability of hand washing facilities, ways of waste disposal and food storage mechanisms in the study area compared to other studies.

Children living in households without hand washing facilities were 3.9 times more likely to develop childhood diarrhea compared to households with hand washing facilities. This finding is in line with studies done in Ghana [14], Benshangul Gumz [19] and East Gojjam [11]. This may be due to the fact that using improved latrine and presence of a hand washing facility decreases the contamination of foods and water by pathogenic organisms. Similarly, in the current study, children whose mother used only water to wash their hand were six times more likely to develop childhood diarrhea than children whose mother used water with soap to wash their hand. This finding is in line with studies done in south-west Ethiopia [20], Jijjiga [21] and Bangladesh [22]. This might be due to soap has antimicrobial agent, and it is effective to prevent diarrhea and occurrence of other hygiene related diseases. Proper hand washing can eliminate microorganisms.

Mothers feeding practices is a vital indicator for a child health. In this study, diarrhea was significantly associated with breastfeeding practices, non exclusive breastfed children were 2.3 times more likely to develop diarrhea than exclusive breastfed children during the first 6 months of their life. This finding is consistent with systematic review studies done in globe [23] and United States [24]. Which could be due to breast milk has its own polysaccharide immunoglobine A that prevents gastroenteritis by coating thegastrointestinal tract. In addition to this, breast milk is natural, safe, appropriate, cheapest and free of contamination from microbes [25]. Therefore, encouraging exclusive breastfeeding for the first 6 months of life is very important to reduce child morbidities and mortalitiesy. On the other hand, the current finding also showed that children who did not use separate feeding material were 5.7 times more likely to develop diarrhea than their counterparts which is in line with studies done in Debre Birhan [26] and Nigeria [27]. The possible reason might be, the materials that were used in common with other family member might be contaminated. Beyound this, caregivers may neglect cleaning of feeding materials that they used for serving food to their child.

\section{Conclusions}

Considering the current study area is urban setting, the prevalence of childhood diarrhea was high. Lack of hand washing facilities, lack of separatly feeding materials for children, not breastfeed exclusively and hand washing practice were predictors of occurrence of diarrhea. Thus, improving handwashing facilities and practices, serving the food to the child with a separate materials and encourage optimal breastfeeding were recommended.

\section{Additional file}

Additional file 1: English questionaire of diarrhea. (DOCX $43 \mathrm{~kb}$ )

\section{Acknowledgments}

The study participants are duly acknowledged for voluntarily responding to the questionnaire (Additional file 1).

Authors are indebted to study participants for their consent to participate.

Funding

Not applicable.

Availability of data and materials

The data sets generated or/and analysed during the current study are not publicly available due to the presence of sensitive (confidential) participants' information but it is available from the corresponding author on reasonable requests.

\section{Authors' contributions}

$T E, W K, K Z, M U$ and TT2 conceived and designed study proposal, supervised data collection, cleaned and feed data to the commuter. AB, TT1 and YM analyzed and interpreted data; drafted the manuscript for important intellectual content. The authors reviewed and revised the draft further and approved the final version for submission.

Ethics approval and conscent to participate

Ethical clearance was obtained from Bahir Dar University, school of the nursing research committee. The objective and importance of the study were explained to the study participants. The study participant also anticipated benefits and risk, and right not to respond if they did not want to respond oo the study questions. Verbal consent was approved by ethical review board.

Consent for publication

It is not applicable.

Competing interests

The authors declare that they have no competing of interest.

\section{Publisher's Note}

Springer Nature remains neutral with regard to jurisdictional claims in published maps and institutional affiliations.

Received: 21 November 2018 Accepted: 26 April 2019

Published online: 14 May 2019

References

1. Gidudu J, et al. Diarrhea: case definition and guidelines for collection, analysis, and presentation of immunization safety data. Vaccine. 2011;29(5): 1053.

2. Organization, W.H., Diarrhoeal disease. 2013. Reference Source, 2015.

3. Organization, W.H., W.U.J.W. Supply, and S.M. Programme. Progress on sanitation and drinking water: 2015 update and MDG assessment: World Health Organization; 2015. https://data.unicef.org/wp-content/uploads/ 2015/12/Progresson-Sanitation-and-Drinking-Water_234.pdf

4. Bartram J, et al. Global monitoring of water supply and sanitation: history, methods and future challenges. Int J Environ Res Public Health. 2014;11(8): 8137-65. 
5. Anteneh ZA, Andargie K, Tarekegn M. Prevalence and determinants of acute diarrhea among children younger than five years old in Jabithennan District, Northwest Ethiopia, 2014. BMC Public Health. 2017;17(1):99.

6. Regassa W, Lemma S. Assessment of diarrheal disease prevalence and associated risk factors in children of 6-59 months old at Adama District Rural Kebeles, Eastern Ethiopia, January/2015. Ethiop J Health Sci. 2016;26(6):581-8.

7. Mohammed S, Tamiru D. The burden of diarrheal diseases among children under five years of age in Arba Minch District, southern Ethiopia, and associated risk factors: a cross-sectional study. Int Sch Res Not. 2014;2014.

8. Mengistie B, Berhane $Y$, Worku A. Prevalence of diarrhea and associated risk factors among children under-five years of age in Eastern Ethiopia: a crosssectional study. Open J Prev Med. 2013;3(07):446.

9. Alambo KA. The prevalence of diarrheal disease in under five children and associated risk factors in Wolitta Soddo Town, Southern, Ethiopia. ABC Res Alert. 2015;3(2).

10. Dessalegn M, Kumie A, Tefera W. Predictors of under-five childhood diarrhea: Mecha District, west Gojam, Ethiopia. Ethiop J Health Dev. 2011; 25(3):192-200.

11. Anteneh A, Kumie A. Assessment of the impact of latrine utilization on diarrhoeal diseases in the rural community of Hulet Ejju Enessie Woreda, East Gojjam Zone, Amhara Region. Ethiop J Health Dev. 2010;24(2).

12. ICF, C.S.a.C.E.a. Ethiopian demographic and health survey; 2016. p. 551

13. Yassin K. Morbidity and risk factors of diarrheal diseases among under-five children in rural Upper Egypt. J Trop Pediatr. 2000;46(5):282-7.

14. Boadi, K.O. and M. Kuitunen, Childhood diarrheal morbidity in the Accra Metropolitan Area, Ghana: socio-economic, environmental and behavioral risk determinants. World Health \& Population, 2005.

15. Siziya S, Muula AS, Rudatsikira E. Diarrhoea and acute respiratory infections prevalence and risk factors among under-five children in Iraq in 2000. Ital J Pediatr. 2009;35(1):8.

16. Ahmed SF, et al. Prevalence of Diarrhoeal disease, its seasonal and age variation in under-fives in. Int J Health Sci. 2010;2(2).

17. Diouf $\mathrm{K}$, et al. Diarrhoea prevalence in children under five years of age in rural Burundi: an assessment of social and behavioural factors at the household level. Glob Health Action. 2014;7(1):24895.

18. Mohammed S, Tilahun M, Tamiru D. Morbidity and associated factors of diarrheal diseases among under five children in Arba-Minch district, Southern Ethiopia, 2012. Sci J Public Health. 2013;1(2):102-6.

19. Mihrete TS, Alemie GA, Teferra AS. Determinants of childhood diarrhea among underfive children in Benishangul Gumuz regional state, north West Ethiopia. BMC Pediatr. 2014;14(1):102.

20. Gebru T, Taha M, Kassahun W. Risk factors of diarrhoeal disease in underfive children among health extension model and non-model families in Sheko district rural community, Southwest Ethiopia: comparative crosssectional study. BMC Public Health. 2014;14(1):395.

21. Hashi A, Kumie A, Gasana J. Prevalence of diarrhoea and associated factors among under-five children in Jigjiga District, Somali Region, Eastern Ethiopia. Open J Prev Med. 2016;6(10):233

22. Luby SP, et al. The effect of handwashing at recommended times with water alone and with soap on child diarrhea in rural Bangladesh: an observational study. PLoS Med. 2011;8(6):e1001052.

23. Lamberti LM, et al. Breastfeeding and the risk for diarrhea morbidity and mortality. BMC Public Health. 2011;11(3):S15.

24. Scariati PD, Grummer-Strawn LM, Fein SB. A longitudinal analysis of infant morbidity and the extent of breastfeeding in the United States. Pediatrics. 1997;99(6):e5.

25. Tewabe T, et al. Exclusive breastfeeding practice and associated factors among mothers in Motta town, East Gojjam zone, Amhara Regional State, Ethiopia, 2015: a cross-sectional study. Int Breastfeed J. 2016;12(1):12.

26. Mamo A, Hailu A. Assessment of prevalence and related factors of diarrheal diseases among under-five year's children in Debrebirehan Referral Hospital, Debrebirehan Town, North Shoa Zone, Amhara Region, Ethiopia. Open Access Libr J. 2014;1(01):1.

27. Florence Nwaoha A, Ohaeri CC, Amaechi EC. Prevalence of diarrhoea, and associated risk factors, in children aged $0-5$ years, at two hospitals in Umuahia, Abia, Nigeria. Cuadernos de Investigación UNED. 2017;9(1):7-14.

\section{Ready to submit your research? Choose BMC and benefit from}

- fast, convenient online submission

- thorough peer review by experienced researchers in your field

- rapid publication on acceptance

- support for research data, including large and complex data types

- gold Open Access which fosters wider collaboration and increased citations

- maximum visibility for your research: over $100 \mathrm{M}$ website views per year

At BMC, research is always in progress.

Learn more biomedcentral.com/submissions 